\section{P-240 CREATING EMOTIONAL RESILIENCE}

Diane Keeley. Rotherham Hospice, Rotherham, UK

10.1136/bmispcare-2017-hospice.265

Historically Rotherham Hospice provided support for counselling and psychology through the provision of clinical psychologist providing one-to-one support to all counselling and psychology patients at all levels. Bereavement services were delivered only through a volunteer befriending service which did not historically have a robust or consistent method of providing supervision and support to volunteers. This service redesign saw the formal introduction of a tiered Psychology and Counselling Service, providing appropriate support to patients and their families across levels 1-4. These four levels provide tiered support ensuring patients are seen at the right time by the most appropriate person. It also saw the introduction of a formal training, supervision and reflection process for all bereavement befriending volunteers. Finally in 2015, the hospice introduced 'Schwartz Rounds' to allow an increased focus on staff emotional well-being as well as patients, families and carers. Schwartz Rounds are monthly meetings for staff and volunteers to come together in a safe environment to think and talk about how it feels to do the work we do. They are not education sessions and they are not used for problem solving, but purely for reflection on emotions and resilience. Each month we will focus on a different case or theme.

Outcomes These changes provided a skilled and dedicated workforce with increased ability to engage in complex communication with patients and families. They also allowed for robust governance in this area, providing supervision and reflection in line with best practice. Likert scaling tools are used in some areas to allow outcomes to be measured. It is often the case that children withdraw or experience behavioural issues when they are dealing with difficult emotions. We have found that teachers report improvements in children's general wellbeing, interaction with others, and performance when they have been attending Sunbeams. Children and young people also say that attending Sunbeams has a positive effect. Staff and volunteers report positive feedback form Schwartz Rounds attendances and measures in relation to sickness and absence will also be monitored in the future.

\section{P-241 A COLLECTIVE APPROACH TO SERVICE DEVELOPMENT}

Vanessa Gibson, Sarah Popplestone Helm. St Richard's Hospice, Worcester, UK

10.1136/bmjspcare-2017-hospice.266

At St Richard's Hospice a multi-professional group including representation from Human Resources, Finance, Administration, Medical Teams, Nursing Teams, Psycho-social and Database Management came together to work in a collaborative manner to develop a gateway service. The gateway service aimed to be multidisciplinary, providing not only a patient helpline but also a single point of contact for all clinical services. The model of service development in place strongly echoed that described by the King's Fund (2017). Key principles included:

- Developing a shared vision and purpose: achieved by review of comparable services, identification of key issues in the patient's pathway through services, working together to ensure smooth and efficient flow of patients through services

- Establishing frequent face to face contact: frequent working group meetings were established, with clear agendas and time for all views to be heard

- Acknowledging and resolving conflicts: different professionals brought different challenges, teams were taken outside their comfort zones exploring services which were not normally part of their remit

- An altruistic approach; although led by two heads of department the project was very much owned by the clinicians and supporting teams. Original time scales were highly fluid to ensure clinicians' needs were met before moving onto the next stage of the project

- Long-term commitment to this project: this is a large project which it was envisaged would take time to complete therefore the group needed to commit to this long term piece of work and to each other.

Results The service now manages all new referrals for three out of four clinical services. Planned progression to manage all referrals will take place in summer 2017. The project is very much owned by the gateway team and steering group members.

Conclusion Collaborative leadership has produced a sustainable way of working for the benefit of our patients and families.

\section{The workforce and workplace}

\section{P-242 IMPLEMENTING A PROJECT TO ENSURE SUCCESS WHEN CHANGING PRACTICE ON AN IN PATIENT-UNIT}

Wendy Pepper, Stacey Bennel, Angie Morris, Rebecca Bhatia, Chris Krajniewski, Sue Thorne. Dorothy House Hospice Care, Bradford on Avon, UK

\subsection{6/bmispcare-2017-hospice.267}

Background Following a review recommendation and to ensure that the in-patient unit was in line with all other departments within the organisation a project was launched to become a paper-light department whilst ensuring successful change management.

Aims To develop a system with agreed terms of reference and budget which focussed on process, reducing duplication, education, safety, equipment, ergonomics and innovation. Also a system that operated in real time and evidenced safety, productivity, capacity, dependency and quality with improved communication between internal and external settings, reducing patient risk and increasing efficiency maximising professionals care time.

Methods A project sponsor from the executive team and project lead were delegated. A core working group was developed and terms of reference agreed. A project plan incorporating risk assessments were produced with task and completion dates which became an essential working document. Monthly meetings were held and communicated to the in-patient unit team and wider organisation. A SystmOne expert was sourced and given protected time 2.5 days a week to work on the design of the system in full consultation with in-patient unit staff ensuring team involvement from the outset. Equipment was sourced and trialled. A group of champions were chosen and trained on the new system. Extensive training was rolled out to all staff and a 'go live' date identified. Supernumerary 
champion support was available for all shifts for the first two weeks following this date. Standard Operating procedures for downtime were put in place and communicated.

Results A very successful implementation of a significant cultural change with no resistance from the team which has achieved the aims.

Conclusions Support and protected time was key, alongside involving the team and listening to their ideas and fears from the outset. By providing champions to work alongside staff they felt secure and protected in their learning

\section{P-243 DRIVING CHANGE IN HOSPICE CARE - REFLECTING ON THE SUCCESSES AND THE SCARS}

Jan Noble, Heather Richardson, Rob George, Penny Hansford, Ruth Sheridan, Jan Thirkettle. St Christopher's Hospice, London, UK

\subsection{6/bmjspcare-2017-hospice.268}

Aim A hospice in South East London has been engaged in a major programme of change to support its new strategic priorities. This presentation will provide an overview of the change management programme.

Methods The hospice recruited a senior manager to work as service development and transformation lead. Her focus was on change that would allow the hospice to reach more people using an increasingly finite resource of people and money.

Results Over the last two years the post-holder has been engaged in projects focused on:

- establishing the new Single Point of Contact

- designing and utilising a case management approach to guide the allocation of our resources (staff, skills and services)

- improving clinical decision making and related communications between professionals

- introducing a new electronic patient records system

- redesigning clinical administration services to better support clinical professionals.

Working closely with the different clinical directors she has adopted an approach broadly reflective of the PDSA cycle to design and implement change. The work has been overseen by a change board. Much of the change planned has been implemented relatively quickly and results are impressive. However, some resistance exists within the workforce, the impact on staff has been significant and further work is required to embed the changes and ensure new ways of working are sustained.

Conclusion Major change is possible within a hospice context, but it is challenging to implement. Dedicated and senior leadership is required to do this successfully; whilst careful attention to engaging staff in building a vision for something different prior to requiring them to change behaviours is a vital step.

\section{P-244 ASPIRING TO BE THE BEST WE CAN BE - A HOSPICE JOURNEY}

Elizabeth Arnold. Earl Mountbatten Hospice, Newport, UK

10.1136/bmjspcare-2017-hospice.269
The Care Quality Commission's (CQC) model of inspection changed in 2014 using a framework encompassing five key questions; is the service safe, effective, responsive, caring and well-led? The hospice planned for the inspection over many months, working with staff, volunteers and trustees to highlight areas of good practice and identify areas that required improving. The whole organisation engaged in workshops and interactive sessions together, fostering recognition that everyone has a responsibility to improve the quality of the services provided and the experiences of people who use our services.

Over 150 staff, trustees and volunteers came together periodically over the course of 18 months and informed us of their perceptions of the organisation's strengths and weaknesses. Through a process of engagement, listening and information gathering we formed a detailed picture of the hospice's position against the CQC's five domains. A detailed action plan was created together with files of 'evidence' for the CQC. The hospice received a rating of 'Outstanding'. It is without question that this achievement was wholly as a result of working together, collective leadership, trust and pride. A number of key themes emerged through this process which may be useful for other providers to replicate:

- What is the best that we can be? - developing a culture where people really believe in the values; these appeared essential to greater levels of engagement

- Leadership is about yourself - every person from 'ward to board' took personal responsibility and were supported to take the initiative and innovate

- Celebration and stories - the promotion of stories was seen as vital to emphasise the impact of what hospices do; one volunteer carried a photograph of an owl 'visiting' a patient to show the CQC should she be working when CQC visited!

- Our challenge is to be 'outstanding' across our entire organisation, every day and always.

\section{P-245 NOW WHERE IS THAT POLICY ON ...}

Paula Powell, Daniel Monnery, Susan Schofield, Charles Hyland, Debbie Jones. Willowbrook Hospice, Merseyside, UK

10.1136/bmispcare-2017-hospice.270

Most specialist palliative care units have clinical policies to support best practice. In addition multiple resources are available to clinical staff as books, clinical guidelines and apps. Our experience at Willowbrook Hospice was that staff would refer to guidelines and formats they were most familiar with even if newer versions were available. Equally comprehensive policies were not referred to because staff could not recall how to find them or when found the pertinent information was not easily accessible.

This represents a risk to patients and the organisation.

This poster describes the work that the medical and nursing teams carried out to develop hospice specific 'quick reference guidelines' for important policies and procedures that distilled the information into an accessible form, usually flow charts. Examples are - hypercalcaemia management, commencing ketamine, recognition and management of delirium and sepsis. 